\title{
Frequency of Lipohypertrophy and Associated Risk Factors in Young Patients with Type 1 Diabetes: A Cross-Sectional Study
}

\author{
Ayman A. Al Hayek · Asirvatham A. Robert - Rim B. Braham · Mohamed A. Al Dawish
}

Received: January 17, 2016/ Published online: March 15, 2016

(C) The Author(s) 2016. This article is published with open access at Springerlink.com

\section{ABSTRACT}

Introduction: The objective of this study was to investigate the frequency of lipohypertrophy (LH) and the associated risk factors in young patients with type 1 diabetes mellitus (T1DM).

Methods: This cross-sectional study was conducted on a sample of 174 patients with T1DM (aged 13-18 years) treated with multiple daily insulin injections for a minimum duration of 1 year. The study was performed at the Diabetes Treatment Center, Prince Sultan Military Medical City (Riyadh, Saudi Arabia), between July 2015 and September 2015. Information regarding patients' age, weight, height, adjusted body mass index (BMI), period of the diabetic condition, length of needle used, number of injections per day, injection locations, insulin regimen, and glycosylated hemoglobin (HbA1c) were

Enhanced content To view enhanced content for this article go to www.medengine.com/Redeem/ 7944F060737E8054.

A. A. Al Hayek $(\bowtie) \cdot$ A. A. Robert · R. B. Braham .

M. A. Al Dawish

Department of Endocrinology and Diabetes,

Diabetes Treatment Center, Prince Sultan Military

Medical City, Riyadh, Saudi Arabia

e-mail: ayman.alhayek@yahoo.com recorded. LH was assessed using the palpation technique.

Results: Nearly $46 \%$ of patients were found to reuse needles, while $42.5 \%$ failed to alternate the injection site and 23\% revealed unexplained hypoglycemic events. A substantial percentage of patients (approximately 47\%) showed grade $1 \mathrm{LH}$, followed by $33.7 \%$ with grade 2 and $19.3 \%$ with grade $3 \mathrm{LH}$. A higher frequency of LH was observed in the thigh region $(n=28,33.7 \%)$ than in the arm, which was second highest ( $n=23,27.7 \%)$. Patients aged $\geq 16$ years showed a higher frequency of LH than those aged $<16$ years. Patients with uncontrolled diabetes mellitus had a greater likelihood of having LH (59.5\%) than those with controlled diabetes (20.8\%). Significant differences in LH were observed based on needle length, needle reuse, and rotation of the injection sites. On performing regression analysis, the independent risk factors for $\mathrm{LH}$ were found to be as follows: higher BMI, higher HbA1c, a higher number of injection sites, a higher rate of needle reuse and failed to alternate the injection site.

Conclusion: As the frequency of LH was found to be high in Saudi patients with T1DM, it is essential to educate patients on the risk factors for LH and on diabetic control. 
Keywords: Glycemic control; Needle reuse; Lipohypertrophy; Type 1 diabetes mellitus; Saudi Arabia

\section{INTRODUCTION}

In Saudi Arabia, type 1 diabetes mellitus (T1DM) has been identified as among the most common endocrine metabolic disorders in children and adolescents, and is accompanied by serious acute and chronic complications [1, 2]. Over the past 3 eras, the incidence T1DM has been rising in Saudi Arabia and the prevalence of T1DM in Saudi Arabian children and adolescents is currently 109.5 per 100,000 people $[1,2]$. T1DM is chiefly characterized by the inability of the pancreas to produce insulin resulting from the autoimmune destruction of the beta cells [3]. Patients need exogenous insulin throughout their lifetime to survive, either via multiple injections every day or via continuous subcutaneous insulin infusion if required [3-5]. For the majority of patients, two or more daily insulin injections are mandatory, with dose adjustments based on blood glucose levels. Injections or an insulin pump can be used to administer insulin [3-5].

Diabetes management involves patients injecting themselves. As this ranks among the chief requirements $[6,7]$, patients must learn the correct injection technique to avoid intramuscular injections and appropriately deliver the insulin into the subcutaneous tissues, as well as to prevent common complications like lipohypertrophy (LH) [8-10]. LH is the most prevalent and recognized local cutaneous complication of insulin therapy $[10,11]$. The significance of this complication is not only cosmetic as it may also influence insulin absorption. However, its effect on glycemic control remains unclear [12].
Several factors are reported to affect the development of $\mathrm{LH}$, such as: the period of insulin usage, gender, body mass index (BMI), injection site, recurrent tissue trauma from failure to rotate injection sites, and the frequency of needle reuse $[8,10,13]$. Although there are important implications of $\mathrm{LH}$ for diabetes, very limited information and research are available on LH, particularly in the young Saudi population $[2,14]$. Therefore, in this study we determined to investigate the frequency of $\mathrm{LH}$ and the associated risk factors in the young populace with T1DM in Saudi Arabia.

\section{METHODS}

\section{Study Design and Setting}

This cross-sectional study was performed on a sample of 174 patients with T1DM (aged 13-18 years). Patients had undergone treatment with multiple daily insulin (MDI) injections for over 1 year at the Diabetes Treatment Center, Prince Sultan Military Medical City (PSMMC, Riyadh, Saudi Arabia), from July 2015 to September 2015. This study was conducted in accordance with the Declaration of Helsinki, and approval for the study protocol was granted by the research ethics committee of the PSMMC. Patients were informed about the aim and methods of the study verbally and in written form. Written consent was received from patients before the completion of study.

\section{Patient Selection Criteria}

All the participants were deliberately and conveniently selected based on their availability during their routine outpatient clinic visits. Information regarding the study, 
its objectives, and the methodology involved was given to the parents and the adolescents, both verbally and in writing. The participants could opt out of the research at any time and no explanations were required.

\section{Inclusion and Exclusion Criteria}

All patients aged 13-18 years old, who were treated with MDI injections, with T1DM, who were followed up for a minimum of 1 year, and having no other concomitant chronic disease were included in the study. Those excluded were patients treated with insulin pump therapy, as well as those with a history of psychopathology, medical instability, or visual, hearing, or cognitive impairment.

\section{Data Collection}

The patients' age, weight, height, adjusted BMI, period of diabetes, needle length, number of injections per day, injection sites, and insulin regimen were recorded.

\section{Body Mass Index}

BMI was computed by dividing the weight in kilograms by the square of height in meters $(\mathrm{kg} /$ $\mathrm{m}^{2}$ ) and BMI $z$ score was also calculated (adjusted for child age and gender). The $z$ score (or SD score) was calculated as per the formula $(\mathrm{Xi}-\mathrm{Mx}) / \mathrm{SD}$, where $\mathrm{Xi}$ is the actual measurement, $\mathrm{Mx}$ is the mean value for that age and gender, and SD is the standard deviation corresponding to that age and gender [15].

\section{Hypoglycemia and Frequent Unexplained Hypoglycemia}

Hypoglycemia was defined as the occurrence of one or more symptoms of hypoglycemia (such as palpitations, tiredness, sweating, strong hunger, dizziness, and tremor) and a confirmed blood glucose level of $\leq 60 \mathrm{mg} / \mathrm{dL} \quad(3.3 \mathrm{mM} / \mathrm{L})$ [8]. Frequent unexplained hypoglycemia was defined as having a hypoglycemic episode one or more times a week in the absence of a definable precipitating event, such as a change in medication, diet, or activity [8].

\section{Glycosylated Hemoglobin}

Information on the participants' most recent insulin dose and glycosylated hemoglobin (HbA1c) values for the blood glucose control were retrieved from their medical records for the research. The HbA1c test is the most reliable form of diabetes diagnostic assessment, providing a good indication of glycemic control. A HbA1c value $<7 \%$ is normally accepted as a good level of control [16].

\section{Lipohypertrophy}

A trained diabetes educator, skilled in performing observation and palpation techniques, assisted in the evaluation of LH in patients. LH values were distinguished as follows: grade $0=$ no change; grade $1=$ visible hypertrophy of fat tissue but with normal consistency on palpation; grade $2=$ intensive fat tissue thickening but with firm consistency; and grade 3 = lipoatrophy [17]. Participants and their caretakers involved in the study were interrogated regarding the methods of administering the insulin and site rotation. All the participants were treated with MDI injections using insulin aspart and insulin glargine therapy. Training was given on routine care; patients were taught to rotate the injection sites daily based on a special scheme: left, right arm/left, right thigh and/or abdominal area. 


\section{Statistical Analysis}

Microsoft Excel 2010 (Microsoft Corporation, Seattle, WA, USA) and SPSS version 20 (SPSS Inc., Chicago, IL, USA) were used to analyze data. Besides the descriptive analysis, Chi-square test was used to find out the associations between $\mathrm{LH}$ and selected factors for statistical significance. Logistic regression was used to determining the role of influencing factors in development of LH. A $P$ value of $<0.05$ was considered statistically significant.

\section{RESULTS}

\section{Participant Characteristics}

Demographic and clinical variables of the study population are presented in Table 1 . The study population had a mean $( \pm \mathrm{SD})$ age of $15.43 \pm 1.97$ years, and included 90 males $(51.7 \%)$ and 84 females (48.3\%). The mean $( \pm \mathrm{SD})$ duration of T1DM diagnosis was $6.1 \pm 4.5$ years. A total of $121(69.5 \%)$ patients were identified with uncontrolled diabetes (HbA1c > 7\%). Nearly $46 \%$ of the patients were found to reuse their needles, while $42.5 \%$ failed to rotate the injection sites and $23 \%$ of patients had unexplained hypoglycemic events. Most patients were revealed to have grade $1 \mathrm{LH}$ (47\%); the rest had grade $2(33.7 \%)$ and grade 3 (19.3\%; Fig. 1). Higher frequency of LH was observed in the thigh area $(n=28,33.7 \%)$ followed by the arm $(n=23,27.7 \%)$.

The frequency of LH based on the different study variables is presented in Table 2 . Patients aged $\geq 16$ years had a higher frequency of LH than those aged $<16$ years. Patients with uncontrolled diabetes had a greater possibility of LH (59.5\%) compared with those with
Table 1 Demographic and clinical variables of the study population

\begin{tabular}{|c|c|c|}
\hline Variables & Frequencies & $\%$ \\
\hline \multicolumn{3}{|l|}{ Gender } \\
\hline Male & 90 & 51.7 \\
\hline Female & 84 & 48.3 \\
\hline \multicolumn{3}{|l|}{ Age, years } \\
\hline$<16$ & 109 & 62.6 \\
\hline$\geq 16$ & 65 & 37.4 \\
\hline \multicolumn{3}{|c|}{ Body mass index, $\mathrm{kg} / \mathrm{m}^{2}$} \\
\hline$\leq 25$ & 121 & 69.5 \\
\hline$>25$ & 53 & 30.5 \\
\hline \multicolumn{3}{|l|}{ Education } \\
\hline Primary & 57 & 32.8 \\
\hline Secondary & 117 & 67.2 \\
\hline \multicolumn{3}{|c|}{ Duration of diabetes, years } \\
\hline$\leq 5$ & 106 & 60.9 \\
\hline$>5$ & 68 & 39.1 \\
\hline \multicolumn{3}{|c|}{ Glycosylated hemoglobin, \% } \\
\hline$\leq 7$ & 53 & 30.5 \\
\hline$>7$ & 121 & 69.5 \\
\hline \multicolumn{3}{|l|}{ Needle reuse } \\
\hline Yes & 80 & 46 \\
\hline No & 94 & 54 \\
\hline \multicolumn{3}{|c|}{ Needle length, mm } \\
\hline 4 & 63 & 36.2 \\
\hline 6 & 38 & 21.8 \\
\hline 8 & 73 & 42 \\
\hline \multicolumn{3}{|c|}{ Dose of insulin, units per $\mathrm{kg}$} \\
\hline$\leq 0.7$ & 30 & 17.2 \\
\hline$>0.7$ & 144 & 82.8 \\
\hline \multicolumn{3}{|l|}{ Rotation } \\
\hline Yes & 100 & 57.5 \\
\hline No & 74 & 42.5 \\
\hline \multicolumn{3}{|c|}{ Grade (total 83) } \\
\hline 1 & 39 & 47 \\
\hline 2 & 28 & 33.7 \\
\hline 3 & 16 & 19.3 \\
\hline \multicolumn{3}{|c|}{ Unexplained hypoglycemic events } \\
\hline Yes & 40 & 23 \\
\hline No & 134 & 77 \\
\hline
\end{tabular}


diabetes under control (20.8\%). Significant differences were observed in the LH depending on BMI, education, duration of DM, needle length, dose of insulin, needle reuse, injection site rotation, and unexplained hypoglycemic events $(P<0.05)$.

All variables that were statistically significant in Chi-square test were added for regression analysis. Regression analysis showed that variables such as higher BMI, higher HbA1c, a higher number of injection sites, higher needle reuse and failed to alternate the injection site were independent risk factors for LH. Variables such as gender, age, education level, duration of T1DM, needle length, dose of insulin, and unexplained hypoglycemic events were not independently significant and their influence on LH is likely dependent on other factors $(P>0.05$; Table 3$)$.

\section{DISCUSSION}

The frequency of and factors influencing LH among the young individuals with T1DM were investigated. LH has been identified in several studies as the most common cutaneous complication resulting from insulin therapy, occurring in almost 50\% of patients with T1DM $[18,19]$. In this study, LH was reported in $47.7 \%$ of the insulin-treated patients with T1DM (with $47 \%$ showing grade $1 \mathrm{LH}, 33.7 \%$ with grade 2 , and $19.3 \%$ with grade 3 ).

One study has recently reported a strong relationship between the occurrence of $\mathrm{LH}$ and the non-rotation of injection sites; implementing the correct rotation technique had the strongest protective value against $\mathrm{LH}$ [8]. It is also supported by the fact that only 5\% of the patients who correctly rotated injection sites had LH, whereas $98 \%$ of the patients with LH either did not rotate the sites or did so incorrectly [8]. In another study, the prevalence of the LH was observed to be higher in patients who neither changed their injection site nor remembered to do so [18]. However, one study reported contradictory findings in which the frequency of LH was not significantly influenced by injection site rotation and stated that several young patients without LH were observed not rotating the injections sites despite repeated instruction [14]. The current study showed that $42.5 \%$ of the study population failed to rotate their injection site. On regression analysis, our study identified

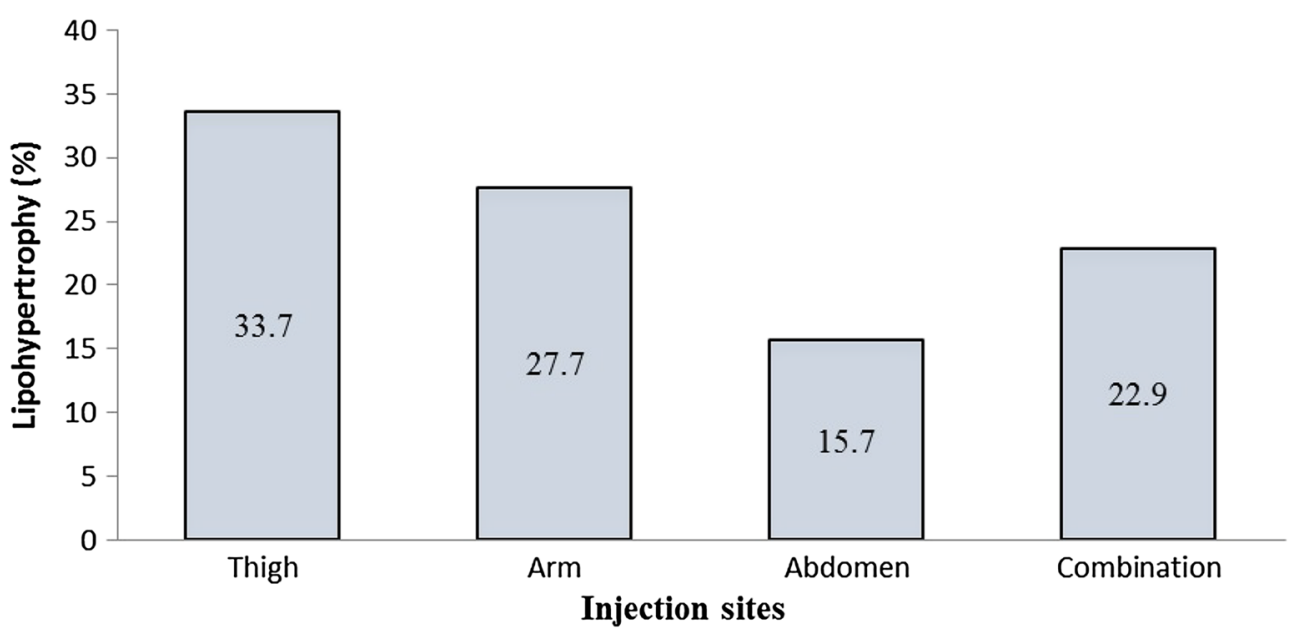

Fig. 1 Frequency of lipohypertrophy at the different injection sites 
Table 2 Frequency of lipohypertrophy and according to relevant characteristics

\begin{tabular}{|c|c|c|c|}
\hline Variables & $\begin{array}{l}\text { No lipohypertrophy } \\
(n=91)\end{array}$ & $\begin{array}{l}\text { Lipohypertrophy } \\
(n=83)\end{array}$ & $P$ value \\
\hline \multicolumn{4}{|l|}{ Gender } \\
\hline Male & $47(52.2)$ & $43(47.8)$ & \multirow[t]{2}{*}{0.207} \\
\hline Female & $44(52.4)$ & $40(47.6)$ & \\
\hline \multicolumn{4}{|l|}{ Age, years } \\
\hline$<16$ & $75(68.8)$ & $34(31.2)$ & \multirow[t]{2}{*}{$<0.05$} \\
\hline$\geq 16$ & $16(24.6)$ & $49(75.4)$ & \\
\hline \multicolumn{4}{|c|}{ Body mass index, $\mathrm{kg} / \mathrm{m}^{2}$} \\
\hline$\leq 25$ & $79(65.3)$ & $42(34.7)$ & \multirow[t]{2}{*}{$<0.05$} \\
\hline$>25$ & $12(22.6)$ & $41(77.4)$ & \\
\hline \multicolumn{4}{|l|}{ Education } \\
\hline Primary & $46(80.7)$ & $11(19.3)$ & \multirow[t]{2}{*}{$<0.05$} \\
\hline Secondary & $45(38.5)$ & $72(61.5)$ & \\
\hline \multicolumn{4}{|c|}{ Duration of diabetes, years } \\
\hline$\leq 5$ & $68(64.2)$ & $38(35.8)$ & \multirow[t]{2}{*}{0.001} \\
\hline$>5$ & $23(33.8)$ & $45(66.2)$ & \\
\hline \multicolumn{4}{|c|}{ Glycosylated hemoglobin, \% } \\
\hline$\leq 7$ & $42(79.2)$ & $11(20.8)$ & \multirow[t]{2}{*}{$<0.05$} \\
\hline$>7$ & $49(40.5)$ & $72(59.5)$ & \\
\hline \multicolumn{4}{|c|}{ Needle length, mm } \\
\hline 4 & $48(76.2)$ & $15(23.8)$ & \multirow[t]{3}{*}{$<0.05$} \\
\hline 6 & $36(94.7)$ & $2(5.3)$ & \\
\hline 8 & $7(9.6)$ & $66(90.4)$ & \\
\hline \multicolumn{4}{|c|}{ Dose of insulin, units per $\mathrm{kg}$} \\
\hline$\leq 0.7$ & $24(80)$ & $6(20)$ & \multirow[t]{2}{*}{$<0.05$} \\
\hline$>0.7$ & $67(46.5)$ & $77(53.5)$ & \\
\hline \multicolumn{4}{|l|}{ Needle reuse } \\
\hline Yes & $23(28.8)$ & $57(71.2)$ & \multirow[t]{2}{*}{$<0.05$} \\
\hline No & $68(72.3)$ & $26(27.7)$ & \\
\hline \multicolumn{4}{|l|}{ Rotation } \\
\hline Yes & $77(77)$ & $23(23)$ & \multirow[t]{2}{*}{$<0.05$} \\
\hline No & $14(18.9)$ & $60(81.1)$ & \\
\hline \multicolumn{4}{|c|}{ Unexplained hypoglycemic events } \\
\hline Yes & $12(30)$ & $28(70)$ & \multirow[t]{2}{*}{$<0.05$} \\
\hline No & $79(59)$ & $55(41)$ & \\
\hline
\end{tabular}

Chi-square test, $P<0.05$ considered as significant 
Table 3 Significant results of logistic regression

\begin{tabular}{lcc}
\hline Variables & Adjusted odds ratio & P value \\
\hline Body mass index, $\mathrm{kg} / \mathrm{m}^{2}$ & \\
$\leq 25$ & 1 & \\
$>25$ & 4.87 & 0.001 \\
Glycosylated hemoglobin, \% & \\
$\leq 7$ & 1 & \\
$>7$ & 4.73 & 0.027
\end{tabular}

Site of lipohypertrophy

$\begin{array}{lll}\text { Thigh } & 1 & \\ \text { Arm } & 2.67 & 0.046 \\ \text { Abdomen } & 1.89 & 0.032 \\ \text { Combination } & 2.73 & 0.043\end{array}$

Needle reuse

\begin{tabular}{lll} 
Yes & 1 & \\
No & 7.47 & 0.001 \\
Rotation & & \\
Yes & 1 & 0.001 \\
No & 5.92 & \\
\hline
\end{tabular}

injection site rotation to be an independent risk factor for LH. Repeated insulin administration injected into a site caused the hypertrophic lipid cells to replace the mid-dermal collagen. Pain sensation was reduced in the LH areas [13]. This is one reason for patients to opt for injections at that site, causing increased dystrophy in the region $[13,20,21]$. It is quite natural that, when the patient feels pain injecting at a site other than the LH area, he or she prefers to inject into the same site, despite knowing the importance of rotating sites $[13,21]$. The majority of the patients in the current study preferred to use the thigh for their insulin injections. LH was reported to frequently occur on both sides of the umbilicus or in the mid-thigh regions, as these are the most convenient and naturally accessible locations for injections. Over time, the area becomes hyposensitive [22].

Needle reuse when injecting insulin is quite common among patients with T1DM [8]. However, as the needle can get deformed with repeated use, it can either raise injection morbidity or, more likely, render the patient susceptible to $\mathrm{LH}$ or induce bleeding at the injection site. The literature contains evidence that the frequent reuse of insulin needles raises the risk of infection [10, 23]. A European epidemiological study on insulin injection techniques indicated that patients who reused needles carried $31 \%$ higher risk of $\mathrm{LH}$ than those who avoided it. The current study showed that $46 \%$ of participants reused the needles, and that $\mathrm{LH}$ was $8 \%$ higher in the patients reusing needles than in those who used fresh ones. Regression analysis highlighted a strong relationship between multiple reuse of a single needle and LH in this study group.

In a recent study, $\mathrm{LH}$ was reported to occur less frequently in patients were obese and overweight versus those who were normal or underweight [14]. Another study recorded a higher BMI to be an independent risk factor for the occurrence of LH [14]. The present study indicated that LH was mainly linked to BMI. Regression analysis performed revealed that LH was an independent risk factor for the HbA1c level in the population under study. Several studies have shown that insulin repeatedly injected into the same site can induce fat and scar tissue accumulation [8, 24]. This results in hard, fatty, and unattractive bumps under the skin in the abdomen or thighs. More significantly, these can interfere with patients' insulin therapy. The tissue masses may impede the insulin absorption, inducing a blood glucose spike, even producing dangerously low glucose levels later. While LH on its own is not life-threatening, it can make the diabetes harder to manage [18]. 
As this study has a significant limitation, having been conducted in a single medical center, more research is warranted. Nevertheless, this study offers important insights into $\mathrm{LH}$, regarding both its frequency and causes, among adolescents with T1DM in Saudi Arabia.

\section{CONCLUSIONS}

In summary, the frequency of LH is clearly high among adolescents with T1DM in Saudi Arabia, emphasizing the importance of educating patients on the risks of $\mathrm{LH}$, the need to correctly rotate the injection sites and to avoid reuse of needles, and on diabetes control. It is also crucial that all patients with diabetes be educated in order to circumvent developing LH, with re-education being mandatory for those with this condition.

\section{ACKNOWLEDGMENTS}

We would like to thank our patients for their participation in the study. No funding or sponsorship was received for this study or publication of this article. All named authors meet the International Committee of Medical Journal Editors (ICMJE) criteria for authorship for this manuscript, take responsibility for the integrity of the work as a whole, and have given final approval for the version to be published.

Disclosures. Ayman A. Al Hayek, Asirvatham A. Robert, Rim B. Braham, and Mohammed A. Al Dawish have nothing to disclose.

Compliance with Ethics Guidelines. This study was conducted in accordance with the
Declaration of Helsinki, and approval for the study protocol was granted by the research ethics committee of the Prince Sultan Military Medical City (Riyadh, Saudi Arabia). Written consent was received from patients before the completion of study.

Open Access. This article is distributed under the terms of the Creative Commons Attribution-NonCommercial 4.0 International License (http://creativecommons.org/licenses/ by-nc/4.0/), which permits any noncommercial use, distribution, and reproduction in any medium, provided you give appropriate credit to the original author(s) and the source, provide a link to the Creative Commons license, and indicate if changes were made.

\section{REFERENCES}

1. Al Dawish MA, Robert AA, Braham R, et al. Diabetes mellitus in Saudi Arabia: a review of the recent literature. Curr Diabetes Rev. 2015. doi:10.2174/ 1573399811666150724095130 .

2. Al-Hayek AA, Robert AA, Braham RB, et al. Frequency and associated risk factors of recurrent diabetic ketoacidosis among Saudi adolescents with type 1 diabetes mellitus. Saudi Med J. 2015;36:216-20.

3. Oikawa Y. Shimada A [Type 1 diabetes]. Nihon Rinsho. 2015;73:1997-2002.

4. Beck JK, Cogen FR. Outpatient management of pediatric type 1 diabetes. J Pediatr Pharmacol Ther. 2015;20:344-57.

5. Thabit H, Hovorka R. Continuous subcutaneous insulin infusion therapy and multiple daily insulin injections in type 1 diabetes mellitus: a comparative overview and future horizons. Expert Opin Drug Deliv. 2015;30:1-12.

6. Davey B, Segal DG. Self-monitoring of blood glucose measurements and glycaemic control in a managed care paediatric type 1 diabetes practice. S Afr Med J. 2015;105:405-7.

7. De Coninck C, Frid A, Gaspar R, et al. Results and analysis of the 2008-2009 insulin injection 
technique questionnaire survey. J Diabetes. 2010;2:168-79.

8. Blanco M, Hernandez MT, Strauss KW, Amaya M. Prevalence and risk factors of lipohypertrophy in insulin-injecting patients with diabetes. Diabetes Metab. 2013;39:445-53.

9. Frid A, Hirsch L, Gaspar R, et al. New injection recommendations for patients with diabetes. Diabetes Metab. 2010;36(Suppl 2):S3-18.

10. Ji J, Lou Q. Insulin pen injection technique survey in patients with type 2 diabetes in mainland China in 2010. Curr Med Res Opin. 2014;30:1087-93.

11. Berard L, Cameron B. Injection technique practices in a population of Canadians with diabetes: results from a recent patient/diabetes educator survey. Can J Diabetes. 2015;39:146-51.

12. Roper NA, Bilous RW. Resolution of lipohypertrophy following change of short-acting insulin to insulin lispro (Humalog). Diabet Med. 1998;15:1063-4.

13. Hajheydari Z, Kashi Z, Akha O, Akbarzadeh S. Frequency of lipodystrophy induced by recombinant human insulin. Eur Rev Med Pharmacol Sci. 2011;15:1196-201.

14. Omar MA, El-Kafoury AA, El-Araby RI. Lipohypertrophy in children and adolescents with type 1 diabetes and the associated factors. BMC Res Notes. 2011;4:290.

15. Al-Hayek AA, Robert AA, Abbas HM, et al. Assessment of health-related quality of life among adolescents with type 1 diabetes mellitus in Saudi Arabia. Saudi Med J. 2014;35(7):712-7.
16. Lukacs A, Varga B, Kiss-Toth E, Soos A, Barkai L. Factors influencing the diabetes-specific health-related quality of life in children and adolescents with type 1 diabetes mellitus. J Child Health Care. 2014;18:253-60.

17. Kordonouri O, Lauterborn R, Deiss D. Lipohypertrophy in young patients with type 1 diabetes. Diabetes Care. 2002;25:634.

18. Hauner H, Stockamp B, Haastert B. Prevalence of lipohypertrophy in insulin-treated diabetic patients and predisposing factors. Exp Clin Endocrinol Diabetes. 1996;104:106-10.

19. Johansson UB, Amsberg S, Hannerz L, et al. Impaired absorption of insulin aspart from lipohypertrophic injection sites. Diabetes Care. 2005;28:2025-7.

20. Hambridge K. The management of lipohypertrophy in diabetes care. Br J Nurs. 2007;16:520-4.

21. Richardson T, Kerr D. Skin-related complications of insulin therapy: epidemiology and emerging management strategies. Am J Clin Dermatol. 2003;4:661-7.

22. de Villiers FP. Lipohypertrophy-a complication of insulin injections. S Afr Med J. 2005;95:858-9.

23. Nagesh VS, Kalra S. Type 1 diabetes: syndromes in resource-challenged settings. J Pak Med Assoc. 2015;65:681-5.

24. Al Ajlouni M, Abujbara M, Batieha A, Ajlouni K. Prevalence of lipohypertrophy and associated risk factors in insulin-treated patients with type 2 diabetes mellitus. Int $\mathrm{J}$ Endocrinol Metab. 2015;13:e20776. 